https://www.journal-imab-bg.org

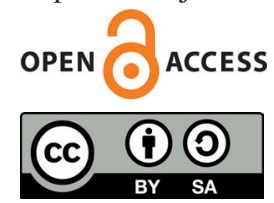

Original article

\title{
OPINION SURVEY OF THE CARDIOLOGISTS IN BULGARIA REGARDING THERAPY WITH ACETYLSALICYLIC ACID, CLOPIDOGREL AND ACENOCOUMAROL IN PATIENTS UNDERGOING DENTAL EXTRACTIONS.
}

\author{
Atanaska Dinkova ${ }^{1}$, Dimitar Atanasov ${ }^{1}$, Lyudmila Vladimirova-Kitova ${ }^{2}$ \\ 1) Department of Oral surgery, Faculty of dental medicine, Medical University \\ - Plovdiv, Bulgaria \\ 2) Clinic of Cardiology, UMBAL "St George", Medical University - Plovdiv, \\ Bulgaria
}

\section{SUMMARY}

Purpose: Cardiovascular diseases are the leading cause of mortality and disability worldwide. Major role in the treatment and prophylaxis of these diseases and their complications has antiplatelet and anticoagulation therapy. Routine practice in the past was an interruption of antiplatelet and anticoagulant medication before dental extraction. Today most authors and dental associations recommend maintaining therapeutic levels of antithrombotic drugs in single or multiple teeth extractions due to the fact that the risk of serious embolic complications outweighs the risk of bleeding. The aim $\mathrm{f}$ the present study is to determine the opinion and approach of cardiologists in Bulgaria regarding therapy with Aspirin, Clopidogrel and Acenocoumarol in patients undergoing dental extractions.

Material and Method: 222 cardiologists were interviewed about their approach in terms of antithrombotic therapy with acetylsalicylic acid (Aspirin), Clopidogrel (Plavix, Trombex) and Acenocoumarol (Sintrom) in patients undergoing dental extractions.

Results: There is no consensus and an established protocol on the cessation of enrolled medications and how long before dental extraction.

Conclusion: There is no approved protocol regarding administration of acetylsalicylic acid (Aspirin) Clopidogrel (Plavix, Trombex) and Acenocoumarol (Sintrom) in patients undergoing teeth extraction. A large number of thromboembolic complications due to interruption of the therapy has been reported.

Keywords: cardiologists, acetylsalicylic acid, clopidogrel, acenocoumarol, tooth extraction

\section{INTRODUCTION}

Cardiovascular disease (CVD) and cerebro-vascular diseases (CVD) are the leading cause of mortality and disability worldwide, as each year CVD cause $1 / 3$ of all deaths worldwide. [1] In Europe CVD causes 47 percent, as in Bulgaria the rate is over 60 percent of all deaths. [2]
Leading in the treatment of these diseases and in the prophylaxis of their complications are antiplatelet and anticoagulation drugs. Millions of people worldwide are taking antithrombotic drugs on a daily basis. Extraction of teeth in these patients requires a special approach. Routine practice in the past was the interruption of antithrombotic medication prior to dental extraction aimed at reduction of the bleeding risk. [3, 4] Nowadays most authors and professional organizations (the American Cardiology Association, American Dental Association, British Dental Association, the American College of Chest surgery, Thrombosis group of Canada, The international society of thrombosis and hemostasis, etc.) recommend maintaining therapeutic levels of the antithrombotic medication with most dental surgical procedures, including single or multiple extractions, due to the fact that the risk of fatal thromboembolic complications overweight the risk of bleeding. [5 - 10] Yet there are still controversial opinions in the literature and in practice. [11, 12]

\section{MATERIAL}

The purpose of the present study is to establish the opinion and approach of cardiologists in Bulgaria regarding the treatment with Acetylsalicylic Acid (Aspirin), Clopidogrel (Plavix, Trombex) and Acenocoumarol (Sintrom) in patients with forthcoming teeth extractions.

A randomized study was conducted by interviewing 222 cardiologists for their approach to the antithrombotic therapy with Acetylsalicylic Acid (Aspirin), Clopidogrel (Plavix, Thrombex) and Acenocoumarol (Sintrom) in patients undergoing dental extractions.

The study was conducted at National Congresses of Cardiology, and various scientific events of the Society of Cardiologists in Bulgaria were used in the period 2015 2016.

\section{METHODS}

Sociological Methods

A questionnaire containing ten questions was devel- 
oped: Gender, professional experience, work placement, percentage of patients taking antithrombotic drugs, approach regarding therapy with Aspirin, Clopidogrel and Acenocoumarol (Sintrom) prior to tooth extraction, postponement of teeth extraction until the end of antithrombotic therapy, thromboembolic complications due to discontinuation of the antithrombotic therapy, hemorrhagic complications after dental extraction. With the exception of work experience and work placement, the respondents indicate one of two, three or four possible answers.

\section{RESULTS}

In the study were included 222 cardiologists, from which 100 men and 122 women. Half of the interviewed cardiologists $(50.0 \%)$ have work experience up to 10 years, between 11 and 20 years work experience have 1/3 (36.5\%) and over 20 years of experience have $13.5 \%$. Most of the surveyed cardiologists $(89.2 \%)$, practice in large settlements with over 100000 inhabitants. (Table 1)

Table 1. Characteristics of the studied contingent

\begin{tabular}{|l|l|c|c|c|}
\hline Characteristics & & Number & Percentage $\%$ & Standard Error \\
\hline \multirow{3}{*}{ Gender } & Male & 100 & $45,0 \%$ & $3,3 \%$ \\
\cline { 2 - 5 } & Female & 122 & $55,0 \%$ & $3,3 \%$ \\
\hline \multirow{3}{*}{ Work experience } & Up to 10 years & 111 & $50,0 \%$ & $3,4 \%$ \\
\cline { 2 - 5 } & $11-20$ years & 81 & $36,5 \%$ & $3,2 \%$ \\
\cline { 2 - 5 } & Over 20 years & 30 & $13,5 \%$ & $2,3 \%$ \\
\hline \multirow{2}{*}{ Work placement } & Over 100 000 & 198 & $89,2 \%$ & $2,1 \%$ \\
\cline { 2 - 5 } & Under 100 000 & 24 & $10,8 \%$ & $2,1 \%$ \\
\hline
\end{tabular}

From the question "Approximately what percentage of your patients take anticoagulant and/or antiplatelet medication?", most of the respondents $(40.5 \%)$ have over $75 \%$ of patients taking antithrombotic drugs. $35.6 \%$ have up to $49 \%$ patients receiving antithrombotic drugs, and $23.9 \%$ of respondents have between 50 and $75 \%$ (Figure 1).

Fig. 1. Share of the patients receiving anticoagulants or antiplatelets.

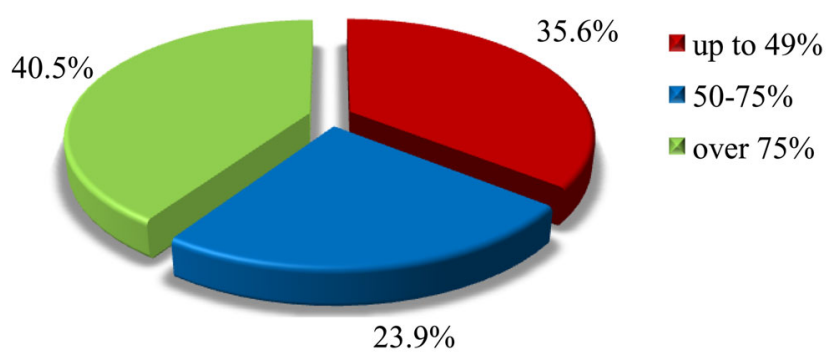

From the next question: "Do you interrupt the intake of Acetylsalicylic Acid (Aspirin) to your patients before teeth extraction?" with possible answers: "No", "Yes", for 48 hours", "Yes, for 72 hours"; $2 / 3$ (61.7\%) of the interviewed cardiologists do not consider necessary to discontinue acetylsalicylic acid before dental extraction. The analysis revealed a statistically significant difference: cardiologists with over $75 \%$ of patients taking antithrombotic drugs in the highest percent did not interrupt drug intake before teeth extraction. $\left(\chi^{2} 28,794\right.$, df 4 , P 0,000). $23.4 \%$ of the interviewed discontinue acetylsalicylic acid for 48 hours, and $14.9 \%$ of respondents considered the interruption to be 72 hours (Figure 2).
Fig. 2. The opinion of the cardiologists according to discontinuation of acetylsalicylic acid (Aspirin) before tooth extraction.

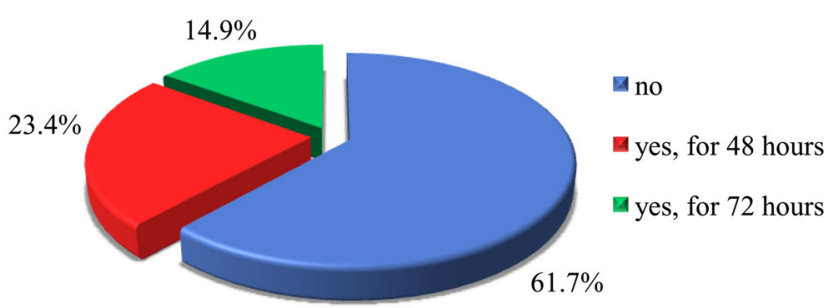

From the question: "Do you interrupt the intake of Clopidogrel to your patients before teeth extraction?", with possible answers: "No", "Yes", for 48 hours", "Yes, for 72 hours"; again predominant opinion among cardiologists $(48.2 \%)$ is for the continuation of the Clopidogrel therapy before dental extraction which coincides with the recommendations of many authors. [12, 13, 14, 15] Here, too, a statistical difference is found: cardiologists with over $75 \%$ of patients receiving antithrombotic drugs in the highest $\%$ do not interrupt drug intake before teeth extraction. $\left(\chi^{2}\right.$ $27,480$, df 4 , P 0,000$), 1 / 3$ of the respondents $(30,2 \%)$ discontinue Clopidogrel intake for $48 \mathrm{~h}$ and $21,6 \%$ of respondents consider for necessary discontinuation of Clopidogrel prior tooth extraction for $72 \mathrm{~h}$ (Figure 3). 
Fig. 3. The opinion of the cardiologists according to discontinuation of Clopidogrel (Plavix, Trombex) before tooth extraction.
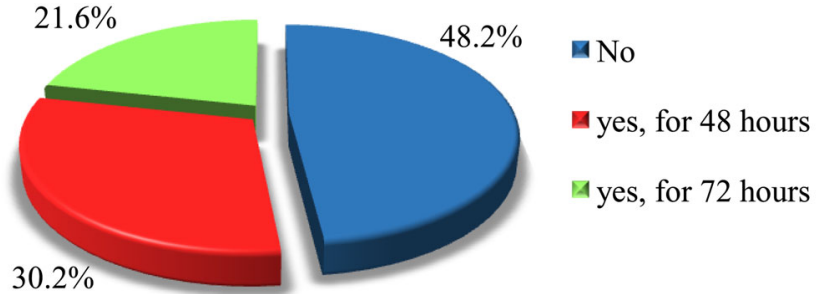

From the next question: "Do you temporarily discontinue Sintrom in your patients before tooth extraction?" with possible answers: "No", "Yes", for 48 hours", "Yes, for 72 hours"; and "Depends on INR level"; half of the respondents $(49.5 \%)$ believe that behaviour is determined by the level of INR, which coincides with the recommendations of most authors in the literature. [5, 7, 8, 16, 17, 18] $36.5 \%$ of respondents believe that Sintrom should be discontinued for 48 hours before teeth extraction, $11.3 \%$ believe that Acenocoumarol should be discontinued for 72 hours and only $2.7 \%$ did not consider interruption of the medication for necessary (Figure 4).

Fig. 4. The opinion of the cardiologists according to discontinuation of Acenocumarol (Sintrom) before tooth extraction.

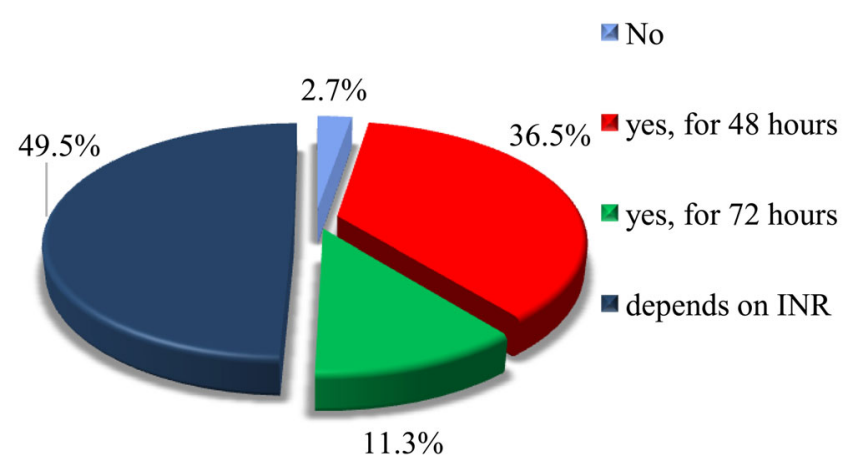

From the question: "Do you postpone teeth extraction until antithrombotic therapy is completed in some patients?" the answers were almost equal. $51.4 \%$ did not postpone compared to $48.6 \%$ who postpone extraction (figure 5). Statistical dependence between work experience and $\%$ of patients taking antithrombotic drugs was found: cardiologists with work experience below 10 years, and those with less than $49 \%$ of patients receiving antithrombotic drugs, more often postpone dental treatment until completion of the antithrombotic therapy. $\left(\chi^{2} 30,710\right.$, df2, P0,000), $\left(\chi^{2} 6,405\right.$, df2, P0,041).
Fig. 5. The share of the cardiologists depending on postponement of the teeth extraction until completion of the antiplatelet therapy.
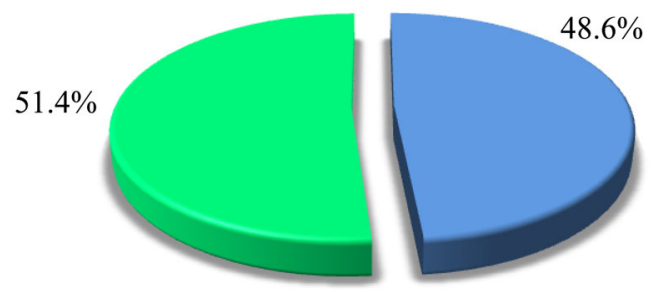

yes

回o

From the question: "Have you had thromboembolic complications in your patients due to discontinuation of the antithrombotic therapy?" $39.6 \%$ report for patients with thrombotic complications due to discontinuation of the therapy (Figure 6). A statistical difference is found: cardiologists with work experience up to 10 years more often report such complications. $\left(\chi^{2} 15,608\right.$, df 2 , P 0,000$)$. Moreover: fewer thromboembolic complications were reported by cardiologists with fewer patients receiving antithrombotic drugs and vice versa $\left(\chi^{2} 14,588\right.$, Df 2, P 0.001)

Fig. 6. The share of the cardiologists reported for thromboembolic complications as a result of discontinuation of the antithrombotic therapy.

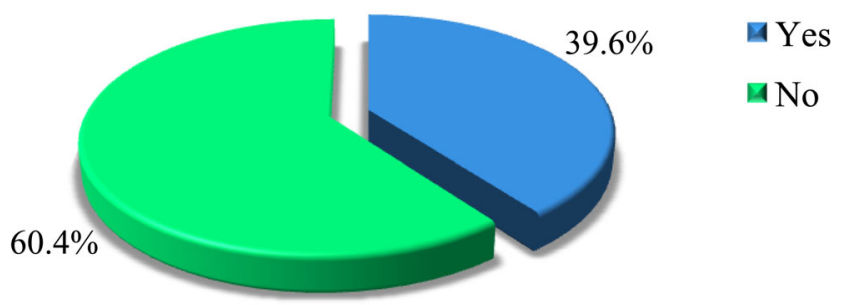

From the next question: "Are you aware of haemorrhagic complications after dental extraction in your patients, treated with an antiplatelet/anticoagulant drug?" $46.4 \%$ reported positive haemorrhagic complications, while $53.6 \%$ gave a negative response (Figure 7 ).

Fig. 7. The share of the cardiologists reported for hemorrhagic complications after dental extraction in patients taking antiplatelet/anticoagulant drug.

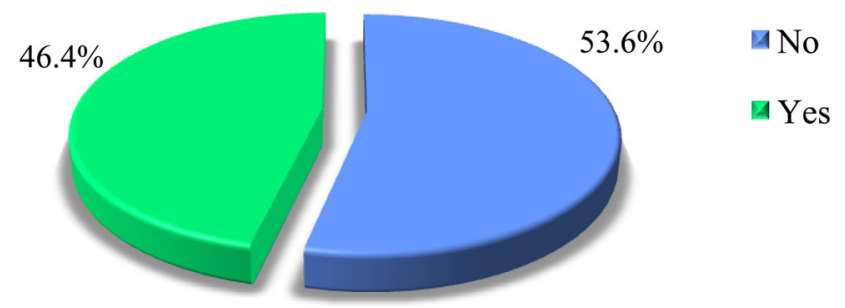




\section{DISCUSSION}

Based on the survey, it was found that a large proportion of the patients in Bulgaria take antithrombotic drugs. Regarding the intake of Acetylsalicylic acid there is no established protocol and unified opinion whether the medication intake should be interrupted and for how long before teeth extraction. The highest percentage of cardiologists $(62 \%)$ do not consider for necessary to discontinue acetylsalicylic acid before tooth extraction, which coincides with most current recommendations. [13, 19, 20, 21]

Similar is opinion regarding intake of Clopidogrel before teeth extraction. Approximately $49 \%$ of the interviewed cardiologists did not consider for necessary discontinuation of the drug, which coincides with the literature and current recommendations. [14, 15]

With regard to Acenocoumarol (Sintrom), again there is no unified opinion and approach whether to stop intake and for how long before tooth extraction. The highest percentage of the interviewed cardiologists $(40.8 \%)$ consider that Acenocoumarol (Sintrom) should be discontinued for 48 hours before tooth extraction, and nearly $50 \%$ of the cardiologists think that behaviour depends on the level of INR.
Thromboembolic complications as a result of discontinuation of the therapy were reported by $40 \%$ of the cardiologists. Postponement of a tooth extraction until completion of the antiplatelet/anticoagulant therapy was the preferred management by $49 \%$ of the interviewed cardiologists.

\section{CONCLUSIONS}

Many patients are taking antithrombotic medications, but there is no approved protocol regarding administration of Acetylsalicylic acid (Aspirin) Clopidogrel (Plaviks, Trombeks) and Acenocoumarol (Sintrom) in patients undergoing teeth extraction. A large number of thromboembolic complications due to interruption of the therapy has been reported. Majority of the cardiologists support non-interference in antiplatelet and anticoagulant therapy with INR in therapeutic range before dental extraction. This corresponds with current global recommendations, taking into account the fact that the risks of serious thromboembolic complications far overweight the risk of haemorrhage.

\section{REFERENCES:}

1. Micha R, Peñalvo JL, Cudhea F, Imamura F, Rehm CD, Mozaffarian D. Association Between Dietary Factors and Mortality From Heart Disease, Stroke, and Type 2 Diabetes in the United States. JAMA. 2017 Mar; 317(9):912-24. [PubMed] [CrossRef]

2. Roth GA, Huffman MD, Moran AE, Feigin V, Mensah GA, Naghavi M, et al. Global and Regional Patterns in Cardiovascular Mortality From 1990 to 2013. Circulation. 2015 Oct; 132 (17):1667-78. [PubMed] [CrossRef]

3. Lemkin SR, Billesdon JE, Davee JS, Leake DL, Kattlove HE. Aspirin-induced oral bleeding: correction with platelet transfusion. A reminder. Oral Surg Oral Med Oral Pathol. 1974 Apr; 37(4):498-501. [PubMed]

4. Ziffer AM, Scopp IW, Beck J, Baum J, Berger AR. Profound bleeding after dental extractions during dicumarol therapy. $N$ Engl J Med. 1957 Feb;256(8):351-3. [PubMed] [CrossRef]

5. Armstrong MJ, Gronseth G, Anderson DC, Biller J, Cucchiara B, Dafer R, et al. Summary of evidencebased guideline: periprocedural management of antithrombotic medications in patients with ischemic cerebrovascular disease: report of the Guideline Development Subcommit- tee of the American Academy of Neurology. Neurology. 2013 May;80(22): 2065-9. [PubMed] [CrossRef]

6. Darawade DA, Kumar S, Desai K, Hasan B, Mansata AV. Influence of aspirin on post-extraction bleeding - A clinical study. J Int Soc Prevent Communit Dent. 2014;4(Suppl:S1):637. [CrossRef]

7. Douketis JD, Spyropoulos AC, Spencer FA, Mayr M, Jaffer AK, Eckman $\mathrm{MH}$ et al. Perioperative management of antithrombotic therapy: Antithrombotic Therapy and Prevention of Thrombosis, 9th ed: American College of Chest Physicians EvidenceBased Clinical Practice Guidelines. Chest. 2012 Feb;141(2 Suppl):e326S50S. [PubMed] [CrossRef]

8. Jimson S, Amaldhas J, Jimson S Kannan I, Parthiban J. Assessment of bleeding during minor oral surgical procedures and extraction in patients on anticoagulant therapy. J Pharm Bioallied Sci. 2015 Apr; 7(Suppl 1): S134-S137. [PubMed]

9. Lockhart PB, Gibson J, Pond SH, Leitch J. Dental management considerations for the patient with an acquired coagulopathy. Part 2: Coagulopathies from drugs. Br Dent J. 2003; 195:405-501. [CrossRef]

10. Yang S, Q Shi, Liu J, Li J, Xu J.
Should oral anticoagulant therapy be continued during dental extraction? A meta-analysis. BMC Oral Health. 2016 Aug;16(1):81. [PubMed] [CrossRef]

11. Iwabuchi H, Imai Y, Asanami S, Shirakawa M, Yamane G, Ogiuchi G, et al. Evaluation of postextraction bleeding incidence to compare patients receiving and not receiving warfarin therapy: a cross-sectional, multicentre, observational study. BMJ Open. 2014 Dec 15;4(12):e005777. [CrossRef]

12. Wahl M. Anticoagulants and Antiplatelet Drugs in Dentistry: Stop the Interruption. RDH I August 2013:89-98

13. Ahmed N, Lakshmi DM, Nazar NM. Aspirin and Dental Extractions: Still A Myth? Int J Pharm Clin Res. 2015 Mar-Apr;7(2):109-112.

14. Ferrari E, Benhamou M, Cerboni P, Marcel B. Coronary Syndromes Following Aspirin Withdrawal A Special Risk for Late Stent Thrombosis. J Am Coll Cardiol. 2005 Feb; 45(3):456-459. [PubMed] [CrossRef]

15. Wahl MJ. Dental surgery in anticoagulated patients. Arch Intern Med. 1998 Aug;158(15):1610-6. [PubMed]

16. Aframian DJ, Lalla RV, Peterson DE. Management of dental patients 
taking common hemostasis-altering medications. Oral Surg Oral Med Oral Pathol Oral Radiol Endod. 2007 Mar; 103(Suppl:S45):e1-11. [PubMed] [CrossRef]

17. Al-Mubarak S, Al-Ali N, Abou Rass M, Al-Sohail A, Robert A, AlZoman K, et al. Evaluation of dental extractions, suturing and INR on postoperative bleeding of patients maintained on oral anticoagulant therapy. British Dent J. 2007 Oct;203(7):E15. [PubMed] [CrossRef]

18. Lip GYH, Frison L, Halperin
JL, Lane DA. Comparative Validation of a Novel Risk Score for Predicting Bleeding Risk in Anticoagulated Patients With Atrial Fibrillation. The HAS-BLED (Hypertension, Abnormal Renal/Liver Function, Stroke, Bleeding History or Predisposition, Labile INR,Elderly, Drugs/Alcohol Concomitantly) Score. J Am Coll Card. 2011 Jan;57(2):173-80. [PubMed]

19. Ardekian L, Gaspar R, Peled M, Brener B, Laufer D. Does low-dose aspirin therapy complicate oral surgical procedures? J Am Dent Assoc. 2000
Mar;131(3):331-5. [CrossRef]

20. Brennan MT, Richard LW, Miller CS. Aspirin and bleeding in dentistry: an update and recommendations. Oral Surg Oral Med Oral Pathol Oral Radiol Endod. 2007 Sep; 104(3): 316-23. [PubMed] [CrossRef]

21. Pettinger TK, Owens CT. Use of low-molecular-weight heparin during dental extractions in a medicaid population. J Manag Care Pharm. 2007 Jan-Feb;13(1):53-8. [PubMed]

Please cite this article as: Dinkova A, Atanasov D, Vladimirova-Kitova L. Opinion survey of the cardiologists in Bulgaria regarding therapy with Acetylsalicylic acid, Clopidogrel and Acenocoumarol in patients undergoing dental extractions. J of IMAB. 2017 Oct-Dec;23(4):1737-1741. DOI: https://doi.org/10.5272/jimab.2017234.1737

Received: 26/06/2017; Published online: 31/10/2017

Address for correspondence:

Atanaska Dinkova, DMD, DDS

Department of Oral Surgery, Faculty of Dental Medicine, Medical University Plovdiv, Bulgaria

E-mail: dinkova_asia@yahoo.com 